\title{
Granule and Solvent for Suspension for Injection Dosage Form
}

National Cancer Institute

\section{Source}

National Cancer Institute. Granule and Solvent for Suspension for Injection Dosage Form. NCl Thesaurus. Code C149545.

Sterile granules and sterile solvent intended for the preparation of a suspension for injection by dispersing the granules in the solvent. 